\title{
Pregnancy and delivery in patients with coronary artery lesions caused by Kawasaki disease
}

\author{
E Tsuda, Y Ishihara, K Kawamata, S Tsukano, R Negi, S Echigo, Y Chiba
}

Heart 2005;91:1481-1482. doi: 10.1136/hrt.2004.058842

$\mathrm{T}$ hirty seven years have passed since the first description of Kawasaki disease (KD) and some women with coronary artery lesions caused by $\mathrm{KD}$ are now of childbearing age $\mathrm{a}^{12}$ The incidence of giant aneurysms leading to ischaemic heart disease among women is about one third that among men. There is little information on managing pregnancy and delivery in patients with coronary artery disease. ${ }^{34}$ We analysed the clinical course of pregnancy and delivery in this population and determined the nature of problems.

\section{PATIENTS AND METHODS}

We encountered 13 pregnancies and deliveries in 10 patients who had coronary artery lesions caused by KD from 1993 to 2004 in our follow up clinic. Their ages at delivery ranged from 18-34 years (median 28 years) (table 1). All patients underwent cardiac catheterisation including selective coronary angiography and left ventriculography before pregnancy. The interval between the latest coronary angiogram and delivery ranged from eight weeks to eight years. All patients underwent a treadmill test and exercise stress radioimmunological myocardial imaging before pregnancy.

\section{RESULTS}

Nine patients had a normal left ventricular ejection fraction, although one patient (patient 1) had an ejection fraction of $43 \%$ caused by asymptomatic myocardial infarction. Three patients (patients 1, 2, and 8) had undergone coronary artery bypass grafting because of stenotic lesions caused by KD. All three patients had grafting to the left anterior descending artery with the internal thoracic artery in two patients and the saphenous vein in the third. One patient also had a graft to the obtuse marginalis with the saphenous vein (patient 1). All patients were in New York Heart Association functional class I, although one patient (patient 1) had a history of being in class II. Table 1 shows the locations of the coronary artery lesions in each patient. Two patients had 75\% localised stenosis of the right coronary artery. Five patients had a giant aneurysm of the right coronary artery and one patient had a giant aneurysm at the bifurcation of the left coronary artery. Although the other three patients had had giant aneurysms previously, the diameter of their aneurysms had decreased. All patients had no significant ischaemic change before pregnancy in the examination.

Nine patients had a vaginal delivery and two patients underwent caesarean section. One patient underwent a caesarean section because of a prolapsed cord at her second delivery. The other patient (patient 3) often noted chest discomfort without ST-T change on the ECG after 30 weeks' gestation. She underwent a caesarean section at 33 weeks' gestation because of bradycardia and slightly decreased oxygen saturation during sleep. After delivery, her symptoms and signs improved spontaneously. She underwent coronary angiography one year after delivery, which showed no significant changes. However, she noted chest discomfort again after 30 weeks' gestation of her second pregnancy. The symptom improved after repeat caesarean section at 34 weeks.

Seven of the 10 vaginal deliveries were assisted, six by forceps use and one by vacuum extraction. Eight vaginal deliveries were performed under epidural anaesthesia. The duration of labour ranged from 3.5 to 8.5 hours and the blood loss from 320 to $950 \mathrm{ml}$.

Medications administered before six pregnancies (table 1) were aspirin $81 \mathrm{mg} /$ day in five and $40 \mathrm{mg}$ of nitrates daily in one. Aspirin was stopped 4-7 days before delivery and restarted 2-7 days after delivery.

None of the 10 patients had a cardiac event and none had ST-T changes on the ECG during pregnancy. Ventricular

Table 1 Coronary artery lesions on coronary angiograms and medication, mode of delivery, and anaesthesia

\begin{tabular}{|c|c|c|c|c|c|c|c|}
\hline \multirow[b]{2}{*}{ Patient } & \multirow{2}{*}{$\begin{array}{l}\text { Age } \\
\text { (years) }\end{array}$} & \multicolumn{2}{|l|}{ Coronary artery lesion } & \multirow{2}{*}{$\begin{array}{l}\text { Delivery } \\
\text { mode }\end{array}$} & \multirow[b]{2}{*}{ Assisted } & \multirow[b]{2}{*}{ Anaesthesia } & \multirow[b]{2}{*}{ Medication } \\
\hline & & RCA & LCA & & & & \\
\hline 1 & 26 & $O C(\operatorname{seg} 1)$ & LAD OC (CABG) LCx OC & Vaginal & Forceps & Epidural & Nitrates $40 \mathrm{mg}$ \\
\hline 2 & 18 & $A N(L)(\operatorname{seg} 1)$ & LAD LS (CABG) & Vaginal & Forceps & Epidural & None \\
\hline 3 & 25 & $\mathrm{AN}(\mathrm{L}) 75 \% \mathrm{LS}(\operatorname{seg} 2)$ & LCA AN(L) LAD 50\%LS (seg 7) & CS & No & General & Aspirin $81 \mathrm{mg}$ \\
\hline 3 & 29 & AN(L) 75\%LS (seg 2) & LCA AN(L) LAD 50\%LS (seg 7) & CS & No & Epidural & Aspirin $81 \mathrm{mg}$ \\
\hline 4 & 29 & $\mathrm{AN}(\mathrm{L})(\operatorname{seg} 1)$ & LCA dilatation & Vaginal & Forceps & Epidural & None \\
\hline 4 & 32 & None & None & Vaginal & Forceps & Epidural & None \\
\hline 5 & 23 & $25 \%$ LS (seg 2) & LCA dilatation & Vaginal & No & None & None \\
\hline 6 & 28 & None & LMT 50\%LS & Vaginal & Vacuum & None & None \\
\hline 6 & 30 & None & LMT 50\%LS & $\mathrm{CS}$ & No & Epidural & None \\
\hline 7 & 28 & AN 25\%LS (seg 1) & LCA dilatation & Vaginal & No & Epidural & Aspirin $81 \mathrm{mg}$ \\
\hline 8 & 34 & AN(L) 50\%LS (seg 1) & LAD OC (CABG) & Vaginal & Forceps & Epidural & none \\
\hline 9 & 28 & None & LCA AN(L) & Vaginal & No & Epidural & Aspirin $81 \mathrm{mg}$ \\
\hline 10 & 28 & $\mathrm{AN}(\mathrm{L}) 75 \% \mathrm{LS}(\mathrm{seg} 1)$ & None & Vaginal & Forceps & Epidural & Aspirin $81 \mathrm{mg}^{*}$ \\
\hline
\end{tabular}

*Compliance was poor.

$A N$, aneurysm; $A N(L)$, giant aneurysm; $C A B G$, coronary artery bypass grafting; $C S$, caesarean section; LAD, left anterior descending coronary artery; $L C A$, left coronary artery; LCx, left circumflex artery; LMT, left main trunk; LS, localised stenosis; OC, complete occlusion; RCA, right coronary artery; seg, segment. 
extrasystoles were detected in eight patients. Unifocal extrasystoles increased during pregnancy and the postdelivery period in two patients.

One patient (patient 7) delivered prematurely because of early rupture of the membranes at 26 weeks' gestation. She had a vaginal haemorrhage at 23 weeks' gestation. She was admitted after two days and discontinued aspirin. She delivered an extremely premature baby of $670 \mathrm{~g}$ with forceps assistance and epidural anaesthesia. The extremely premature baby had a visual disorder caused by premature retinopathy.

\section{DISCUSSION}

The most important problem in pregnancy and delivery for patients with coronary artery disease caused by $\mathrm{KD}$ is possible thrombosis of a coronary artery leading to acute myocardial infarction, which can greatly affect the prognosis of both mother and fetus. One review estimated the incidence of myocardial infarction in pregnancy at 1 in $10000 .^{3}$ None of our patients had cardiac events relating to thrombosis. Low dose aspirin is considered to be safe for pregnancy and delivery. ${ }^{5}$ Only four of our patients were taking aspirin, one of whom had a premature delivery. The relation, if any, between vaginal haemorrhage and the effect of aspirin is unknown. The need for an antithrombotic agent and its form should be determined based on balancing risks of treatment with risks of cardiac and obstetric complications, and on the extent of the coronary artery lesions caused by KD.

Nine patients underwent vaginal delivery without any cardiac complications. An assisted second stage of labour with epidural anaesthesia is preferred for patients with cardiac disease because it helps to maintain stable haemodynamic function and to decrease the burden on the heart by shortening delivery time. If patients have symptoms, a caesarean section should be considered.

An assisted second stage of labour with epidural anaesthesia is preferred for patients with coronary artery lesions caused by KD. Although low dose aspirin for prevention of myocardial infarction is considered to be useful, further investigation for treatment with an antithrombotic agent during pregnancy based on the extent of the coronary artery lesions will be needed. The experience will need to be formulated by careful management in pregnancy and delivery in this population in the future.

\section{Authors' affiliations}

E Tsuda, S Tsukano, S Echigo, Department of Paediatrics, National Cardiovascular Center, Osaka, Japan

Y Ishihara, K Kawamata, R Negi, Y Chiba, Department of Obstetrics, National Cardiovascular Center, Osaka, Japan

Correspondence to: Dr Etsuko Tsuda, Department of Paediatrics, National Cardiovascular Center, 5-7-1 Fujishirodai, Suita-shi, Osaka, 565-8565, Japan; etsuda@hsp.ncvc.go.jp

Accepted 2 February 2005

\section{REFERENCES}

1 Nolan TE, Savage RW. Peripartum myocardial infarction from presumed Kawasaki's Disease. South Med J 1990;83:1360-1.

2 Shear R, Leduc. Successful pregnancy following Kawasaki disease. Obstet Gynecol 1999;94:841.

3 Nolan TE, Hankins GD. Myocardial infarction in pregnancy. Clin Obstet Gynecol 1989;32:68-75.

4 Collins JS, Bossone E, Eagle KA, et al. Asymptomatic coronary artery disease in a pregnant patient: a case report and review of literature. Herz 2002;27:548-54

5 Sibai BM, Mirro R, Chesney CM, et al. Low-dose aspirin in pregnancy. Obstet Gynecol 1989;74:551-6.

\section{STAMPS IN CARDIOLOGY}

\section{The ECG on stamps}

$\mathrm{T}$

he Kingdom of Tonga released a set of four stamps to commemorate 30 years

membership of the Commonwealth. These covered supporting education, the arts, agriculture, and health. The health stamp design includes medicine, surgery, nursing, and, in the background, the electrocardiogram. Flags of the Commonwealth states frame the design.

M K Davies A Hollman

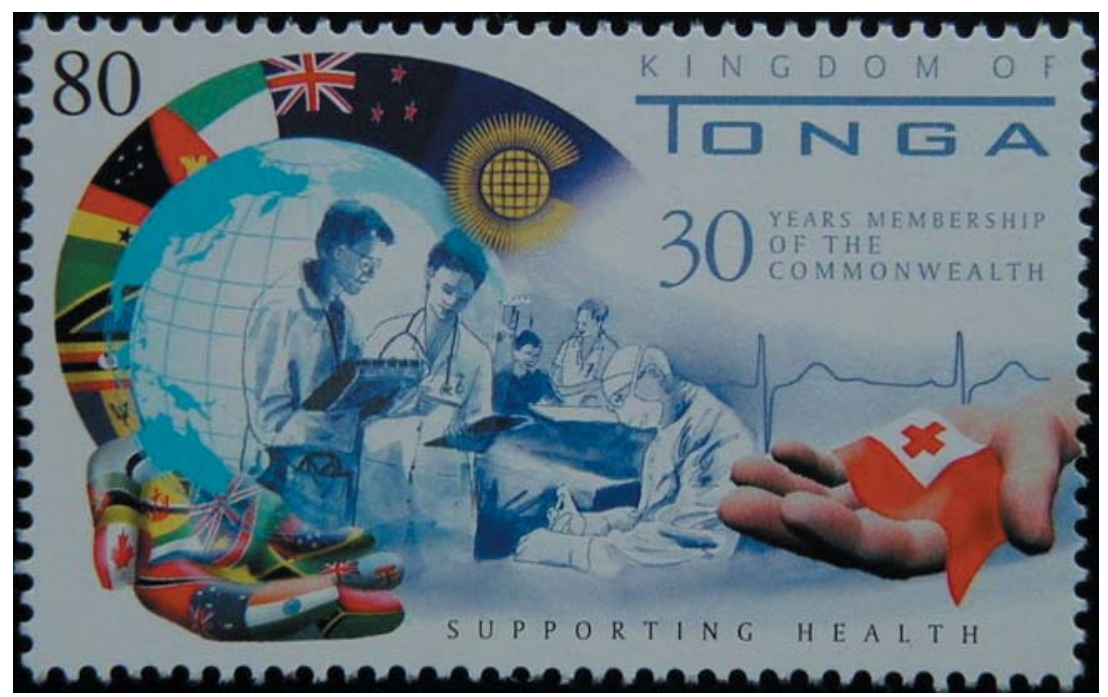

